\title{
Inadequate Sedation During Therapeutic Paralysis: Use of Bispectral Index in Critically Ill Patients
}

\author{
Chelsea L. Tasaka, ${ }^{3,4}$ Jeremiah J. Duby ${ }^{1,4,5} \cdot$ Komal Pandya ${ }^{2}$. \\ Machelle D. Wilson ${ }^{1} \cdot$ Kimberly A. Hardin ${ }^{1}$
}

Published online: 28 May 2016

(c) The Author(s) 2016. This article is published with open access at Springerlink.com

\begin{abstract}
Background Patients receiving therapeutic paralysis may experience inadequate sedation due to intrinsic limitations of behavioral sedation assessment. Bispectral index $\left(\mathrm{BIS}^{\mathrm{TM}}\right)$ provides an objective measure of sedation; however, the role of $\mathrm{BIS}^{\mathrm{TM}}$ is not well defined in intensive care unit (ICU) patients on neuromuscular blocking agents (NMBA).

Objective The aim of this study was to delineate the relationship between BIS $^{\mathrm{TM}}$ and level of sedation for critically ill patients during therapeutic paralysis.

Methods This was a retrospective observational study conducted in ICU patients receiving continuous infusion NMBA and BIS ${ }^{\mathrm{TM}}$ monitoring. The primary endpoint was the correlation of BIS ${ }^{\mathrm{TM}}<60$ during therapeutic paralysis with a Richmond Agitation Sedation Score (RASS) of -4 to -5 (i.e., deep or unarousable sedation) at the time of emergence from therapeutic paralysis.
\end{abstract}

Chelsea L. Tasaka

cltasaka@gmail.com

1 University of California, Davis Medical Center, Sacramento, CA, USA

2 University of Kentucky Medical Center, Lexington, KY, USA

3 Present Address: Department of Pharmacy, University of California San Francisco Medical Center, 505 Parnassus Avenue, San Francisco, CA 94143, USA

4 University of California, San Francisco, School of Pharmacy, San Francisco, CA, USA

5 Touro University, College of Pharmacy, Vallejo, CA, USA
Results Thirty-one patients were included in the analysis. Three of these patients ( $9.6 \%$ ) were inadequately sedated upon emergence from paralysis; that is, restless or agitated (RASS +1 to +2 ). We did not observe a correlation between BIS $^{\mathrm{TM}}$ and RASS upon emergence from paralysis $(r=0.27, p=0.14)$. The sensitivity of $\mathrm{BIS}^{\mathrm{TM}}<60$ in predicting deep sedation (RASS -5 to -4 ) was $100 \%$ (95\% confidence interval [CI] $0-100$ ) with a positive predictive value of $35.7 \%$. The sensitivity and positive predictive value of $\mathrm{BIS}^{\mathrm{TM}}<60$ in predicting light sedation or deeper (RASS -5 to -2 ) was $92.9 \%$ (95\% CI $83.3-100)$ and $92.9 \%$, respectively.

Conclusion These results suggest that 1 in 10 critically ill patients receiving therapeutic paralysis may be inadequately sedated. BIS ${ }^{\mathrm{TM}}$ monitoring may serve as a useful adjunctive measure of sedation in critically ill patients receiving therapeutic paralysis.

\section{Key Points}

Currently, there is no reliable method to measure level of sedation in therapeutically paralyzed patients in the intensive care unit (ICU).

We did not observe a correlation between bispectral index during paralysis and Richmond Agitation Sedation Score (RASS) upon emergence from paralysis.

Despite efforts to provide adequate sedation, as many as one in ten critically ill patients receiving therapeutic paralysis may be inadequately sedated.

Bispectral index may be useful as an adjunct measure of sedation in this clinical scenario. 


\section{Introduction}

The use of neuromuscular blocking agents (NMBA) in the intensive care unit (ICU) is typically limited to salvage therapies involving mechanical ventilation [1]. However, the perspective and practice of therapeutic paralysis is changing in response to a clinical trial that demonstrated mortality benefit in patients with early, severe acute respiratory distress syndrome (ARDS) [2]. Currently, there is no standard method or validated tool for managing sedation to facilitate therapeutic paralysis in critically ill patients. While vital signs may be a signal of pain or agitation, they are unreliable indicators and should not be used in isolation in the assessment of pain or agitation [3].This void in clinical monitoring exposes patients to both unique and putative complications of over- and under-sedation, such as conscious paralysis, prolonged mechanical ventilation, and psychological sequelae. Previous studies have focused on ICU-acquired weakness as the chief safety concern $[1,2]$; there are signals supporting the probability of inadequate sedation with NMBA use in the ICU. A small observational study conducted in a surgical ICU found that $36 \%$ of patients were able to recall events during therapeutic paralysis [4]. Additionally, sustained periods of increased alpha activity-signaling possible awareness-were observed on electroencephalography (EEG) in a sleep study of patients undergoing therapeutic paralysis, suggesting possible awareness [5].

The Society of Critical Care Medicine's Pain, Agitation and Delirium Guidelines suggest that bispectral index $\left(\mathrm{BIS}^{\mathrm{TM}}\right)$ may be used to assess sedation in patients receiving NMBAs; however, no specific recommendations (e.g., BIS ${ }^{\mathrm{TM}}$ target range) are provided for this patient population [3]. The BIS ${ }^{\mathrm{TM}}$ is an objective, non-invasive measure of brain function derived from EEG data and converted by mathematical algorithms into a continuous numerical value ranging from 0 to 100 , with 100 representing full awareness and 0 representing no brain activity. It is more practical than a full EEG for monitoring sedation in the ICU as it requires fewer electrodes and is much simpler to interpret. BIS ${ }^{\mathrm{TM}}$ monitoring is used in patients undergoing general anesthesia to mitigate the risk of awareness [6, 7]; however, the role of BIS ${ }^{\mathrm{TM}}$ has not been clearly defined in patients undergoing therapeutic paralysis in the ICU. Studies show varying correlation between BIS $^{\mathrm{TM}}$ and sedation scales in non-paralyzed ICU patients; however, behavioral sedation scales are not valid in this population due to patients' inability to communicate or move [8-16]. Moreover, there are indications that neuromuscular blockade alone may affect BIS [17].

The purpose of this study was to delineate the relationship between patients' BIS ${ }^{\mathrm{TM}}$ and level of sedation for critically ill patients during therapeutic paralysis. The primary endpoint was correlation of BIS ${ }^{\mathrm{TM}}<60$ upon emergence from therapeutic paralysis with a Richmond Agitation Sedation Score (RASS) of -4 to -5 (i.e., deep or unarousable sedation). Secondary endpoints included sensitivity of BIS $^{\mathrm{TM}}<60$ while on NMBA therapy in predicting sedation level (i.e., RASS -5 to -4 or RASS -5 to -2 ).

\section{Methods}

This was a retrospective observational study conducted at a large academic medical center in patients 18 years of age or older that concurrently received continuous NMBAs and $\mathrm{BIS}^{\mathrm{TM}}$ monitoring in the ICU. Patients were excluded if they received NMBAs for management of intracranial hypertension, were in a persistently obtunded state, or if they did not have adequate documentation of BIS ${ }^{\mathrm{TM}}$ and RASS values. Patients were also excluded if there was a reduction in sedative or analgesic medications between the last recorded BIS ${ }^{\mathrm{TM}}$ while on NMBAs and emergence from paralysis, as this violated the assumption that the level of sedation at these two points in time were comparable. Conversely, patients with an increase in dose of continuous sedative or analgesic medications between these two points in time were included. This would increase the potential to capture patients who had been under-sedated prior to discontinuing the NMBA.

The primary team managed therapeutic paralysis, sedation, and analgesia for each patient. The primary team also determined whether BIS ${ }^{\mathrm{TM}}$ was monitored and whether this was used for titration of sedation for each patient. Sedation was routinely measured and documented with RASS in all ICU patients. As RASS is an inappropriate measure of the level of sedation in paralyzed patients, sedative drug dosage was either kept at a fixed rate or titrated using the BIS ${ }^{\mathrm{TM}}$ device (Aspect Medical Systems A-2000 ${ }^{\mathrm{TM}}$ BIS Monitoring System model 185-0205, Aspect Medical Systems, Inc. Natick, MA, USA).

BIS $^{\mathrm{TM}}<60$ was typically targeted based upon suggested manufacturer data from anesthesia literature where a level $<60$ was associated with a probability of low recall $[6,7,18,21]$.

In the absence of a direct means to measure behavior during therapeutic paralysis, time of emergence from paralysis after discontinuation of NMBAs was selected as the surrogate observational point for assessment of sedation (Fig. 1). This allowed behavioral assessment of the patient using RASS when the paralytic effect had dissipated for comparison with the preceding $\mathrm{BIS}^{\mathrm{TM}}$ while receiving NMBAs. Time of emergence from paralysis was defined as the first time one of the following criteria were met after discontinuation of neuromuscular blockade: return of four 


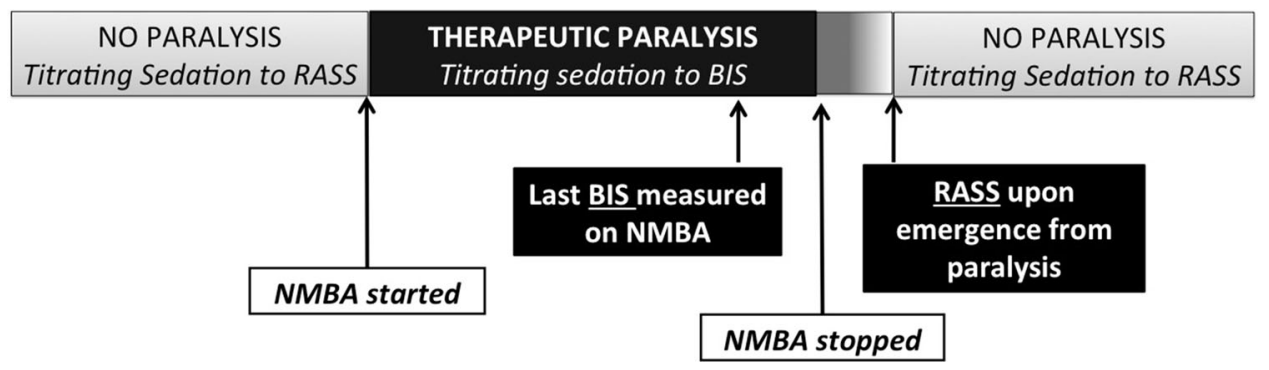

Fig. 1 Study design timeline. This diagram represents the timeline for patients receiving NMBA in the ICU also showing the temporal relationship of key events and data points used in the study. BIS
Bispectral index, ICU intensive care unit, NMBA neuromuscular blocking agent, RASS Richmond Agitation Sedation Scale
Fig. 2 Richmond Agitation Sedation Scale (RASS) [19] and Bispectral Index (BIS) range [18]

\begin{tabular}{|cc|}
\hline RASS & DESCRIPTION \\
\hline+4 & Combative \\
\hline+3 & Very Agitated \\
\hline+2 & Agitated \\
\hline+1 & Restless \\
\hline 0 & Alert and calm \\
\hline-1 & Drowsy \\
\hline-2 & Light sedation \\
\hline-3 & Moderate sedation \\
\hline-4 & Deep sedation \\
\hline-5 & Unarousable \\
\hline
\end{tabular}

\begin{tabular}{|cc|}
\hline BIS & DESCRIPTION \\
\hline 100 & Awake \\
\hline 80 & $\begin{array}{c}\text { Light/moderate } \\
\text { sedation }\end{array}$ \\
\hline 60 & General anesthesia \\
\hline 40 & Deep hypnotic state \\
\hline 20 & Burst suppression \\
\hline 0 & Flat line EEG \\
\hline
\end{tabular}

out of four twitches of the facial or radial nerve (train of four, TOF 4/4), respiratory rate greater than the set ventilator rate, or nurse documentation of patient movement. The RASS on emergence from paralysis was defined as the RASS documented at this time or within 30 minutes after emergence from paralysis. If patients did not meet any of these criteria, then initial titration in sedative and/or analgesic medication was used as a signal of emergence from paralysis. Levels of sedation were defined by the criteria specified in the RASS behavioral sedation assessment tool (Fig. 2) [19]. Inadequate sedation upon emergence from therapeutic paralysis was narrowly defined by the sedative range from 'sustained awakening to voice' through 'combative' (RASS -1 to +4 ). Doses of sedative and analgesic medications were not included in the analysis as this was beyond the scope of this study.

\subsection{Statistical Analysis}

Demographic data included age, sex, date of NMBA initiation, primary service, and Sequential Organ Failure Assessment (SOFA) score [20]. Independent variables included the last $\mathrm{BIS}^{\mathrm{TM}}$ documented prior to discontinuation of NMBA and RASS at the time of emergence from paralysis.

For $\alpha=0.05$, a sample size of at least 13 subjects would provide $80 \%$ power to detect a correlation of 0.7 or greater and a sample size of at least 16 subjects would provide $80 \%$ power to detect a specificity or sensitivity of $0.8 \pm 0.2$. To assess the relationship between BIS ${ }^{\mathrm{TM}}$ and RASS, the Pearson correlation coefficient was determined. Linearity was validated using residual plots from the regression model. The sensitivity and specificity of BIS $^{\mathrm{TM}}<60$ in predicting unarousable to deep levels of sedation (RASS -5 to -4 ) upon emergence from paralysis were calculated. In the absence of a well defined target level of sedation during therapeutic paralysis, the sensitivity and specificity of $\mathrm{BIS}^{\mathrm{TM}}<60$ in predicting light sedation or deeper were also calculated.

\section{Results}

Four hundred thirty-seven patients were screened for inclusion. The majority of excluded patients did not have BIS $^{\mathrm{TM}}$ values charted (Fig. 3). There were 31 patients 


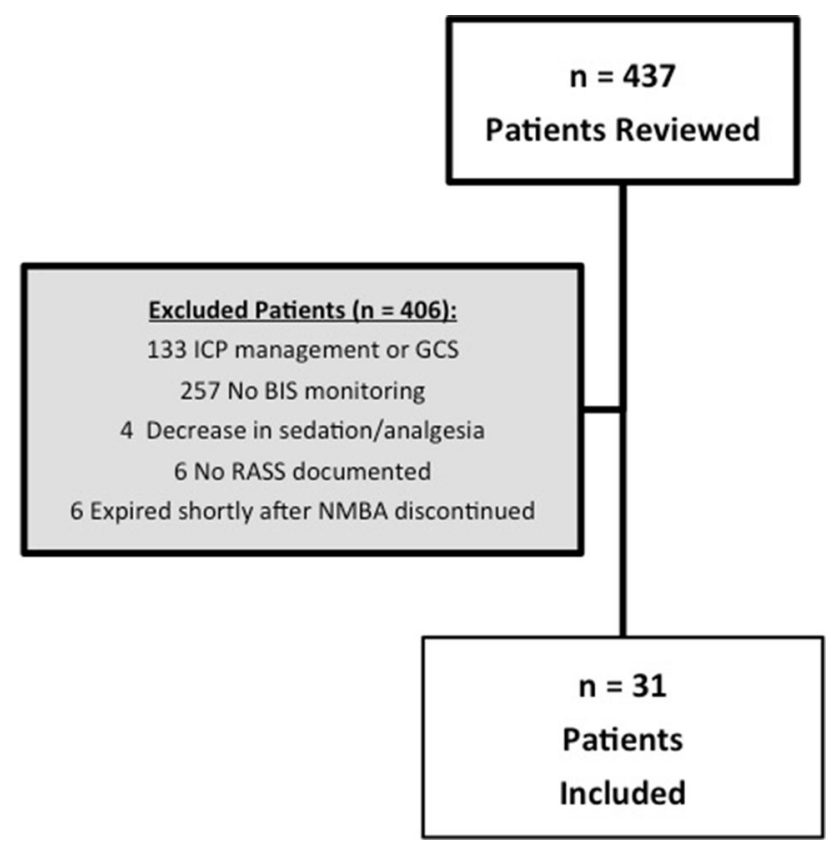

Fig. 3 Included and excluded patients. $B I S$ Bispectral index, GCS Glasgow Coma Scale, ICP intracranial pressure, $N M B A$ neuromuscular blocking agent, RASS Richmond Agitation Sedation Scale

included in the study analysis. Demographic data are summarized in Table 1 . Over half the patients included were admitted to the medical ICU service $(58 \%, 18 / 31)$ and received NMBAs for management of ARDS (61.3\%, 19/31).

Ninety percent $(28 / 31)$ of patients had a BIS $^{\mathrm{TM}}<60$ during paralysis. The majority of patients $(61.3 \%, 19 / 31)$ had a RASS upon emergence from paralysis reflecting unarousable to deep levels of sedation (RASS -5 to -4 , Fig. 2). Three patients (9.6\%) were restless or agitated (RASS +1 to +2 ) on emergence from paralysis.

Among patients with BIS $^{\mathrm{TM}}<60$ during paralysis $(n=28), 26$ patients $(92.9 \%, 95 \%$ confidence interval [CI] 83.3-100) had a level of sedation ranging from unarousable to light (RASS -5 to -2 ) upon emergence from paralysis (Table 3$)$. Eighteen patients $(64 \%, 95 \%$ CI $46.5-82$ ) with BIS $^{\mathrm{TM}}<60$ were unarousable or deeply sedated (RASS -5 or -4 ) upon emergence from paralysis (Table 2). Ten patients in the study had discordant RASS and $\mathrm{BIS}^{\mathrm{TM}}$ values (RASS -3 to +2 despite $\mathrm{BIS}^{\mathrm{TM}}<60$ ).

The observed correlation between BIS ${ }^{\mathrm{TM}}$ during paralysis and RASS upon emergence from paralysis was not statistically significant $(r=0.27, p=0.14$, Fig. 4). No indication of non-linearity was observed in the residual diagnostics.

The sensitivity of $\mathrm{BIS}^{\mathrm{TM}}<60$ in predicting an unarousable to deep level of sedation (RASS of -5 to -4 ) on emergence from paralysis was $100 \%$ (95\% CI 0-100) with a positive predictive value of $35.7 \%$ (Table 2).
Table 1 Demographic data

\begin{tabular}{|c|c|}
\hline Age [mean years, SD] & $45.6 \pm 16.1$ \\
\hline Male $[n(\%)]$ & $17(54.8 \%)$ \\
\hline SOFA score [mean, SD] & $10.3 \pm 3.3$ \\
\hline \multicolumn{2}{|l|}{ Primary service $[n(\%)]$} \\
\hline Medical ICU & $18(58.1 \%)$ \\
\hline Trauma ICU & $3(9.7 \%)$ \\
\hline Burn ICU & $8(25.8 \%)$ \\
\hline Neurosurgical ICU & $1(3.2 \%)$ \\
\hline Cardiothoracic surgery ICU & $1(3.2 \%)$ \\
\hline No change in sedation/analgesia doses ${ }^{a}$ & $17(55 \%)$ \\
\hline Increase in sedation and/or analgesia doses ${ }^{\mathrm{a}}$ & $14(45 \%)$ \\
\hline \multicolumn{2}{|l|}{ Sedative/analgesic received $[n(\%)]$} \\
\hline Continuous propofol/midazolam and opioid ${ }^{\mathrm{b}}$ & $23(74.2 \%)$ \\
\hline Continuous propofol/midazolam only & $5(16.1 \%)$ \\
\hline Opioid $^{\mathrm{b}}$ only & $3(9.7 \%)$ \\
\hline \multicolumn{2}{|l|}{ Indication for NMBA $[n(\%)]$} \\
\hline ARDS & $19(61.3 \%)$ \\
\hline Facilitation of ECLS & $2(6.4 \%)$ \\
\hline Other respiratory & $7(22.6 \%)$ \\
\hline Other & $3(9.7 \%)$ \\
\hline
\end{tabular}

How emergence from paralysis was defined [ $n(\%)]$

Nurse documentation of patient movement

$18(58.1 \%)$

Train-of-four $4 / 4$

$8(25.8 \%)$

Other $^{\mathrm{c}}$

$5(16.1 \%)$

$A R D S$ acute respiratory distress syndrome, ECLS extracorporeal life support, ICU intensive care unit, $N M B A$ neuromuscular blocking agent, SOFA Sequential Organ Failure Assessment

a Between the time the last bispectral index on NMBA was recorded and emergence from paralysis

b Continuous intravenous opioid

${ }^{c}$ Respiratory rate greater than set ventilator rate or titration of sedative/analgesic medications

The sensitivity and positive predictive value of BIS $^{\mathrm{TM}}<60$ in predicting an unarousable to light level of sedation (RASS -5 to -2 ) on emergence from paralysis was $92.9 \%$ (95\% CI 83.3-100) and $92.9 \%$, respectively.

The specificity of $\mathrm{BIS}^{\mathrm{TM}}>60$ in predicting moderate sedation or lighter (RASS -3 to +4 ) on emergence from paralysis was $23.1 \%$ (95\% CI 17-46). The specificity of $\mathrm{BIS}^{\mathrm{TM}} \geq 60$ in predicting inadequate sedation (RASS -1 to $+4)$ upon emergence was $33.3 \%(95 \%$ CI $0-86.7)$ (Table 3).

\section{Discussion}

Approximately 9 in 10 patients with $\mathrm{BIS}^{\mathrm{TM}}<60$ during therapeutic paralysis were unarousable to lightly sedated (RASS -5 to -1 ) upon emergence from paralysis. These 
Table 2 Sensitivity and specificity for deep sedation

\begin{tabular}{|c|c|c|c|c|}
\hline & & \multicolumn{2}{|l|}{ RASS on emergence from paralysis } & \\
\hline & & $\begin{array}{l}\text { Unarousable to deep sedation (RASS } \\
-5 \text { to }-4 \text { ) }\end{array}$ & $\begin{array}{l}\text { Moderate sedation to agitation (RASS } \\
-3 \text { to }+2 \text { ) }\end{array}$ & \\
\hline \multirow[t]{3}{*}{$\begin{array}{l}\text { Last BIS on } \\
\text { NMBA }\end{array}$} & $\mathrm{BIS}<60^{\mathrm{a}}$ & 18 & 10 & $\begin{array}{l}\text { Positive predictive } \\
\text { value }=35.7 \%\end{array}$ \\
\hline & \multirow[t]{2}{*}{$\mathrm{BIS} \geq 60^{\mathrm{a}}$} & 0 & 3 & $\begin{array}{l}\text { Negative predictive } \\
\text { value }=100 \%\end{array}$ \\
\hline & & Sensitivity $=100 \%(95 \%$ CI $0-100)$ & Specificity $=23.1 \%(95 \%$ CI $17-46)$ & \\
\hline
\end{tabular}

$B I S$ Bispectral index, $C I$ confidence interval, NMBA neuromuscular blocking agent, RASS Richmond Agitation Sedation Scale

${ }^{a}$ BIS $<60$ is considered consistent with general anesthesia or deep anesthesia per device manufacturer [18]

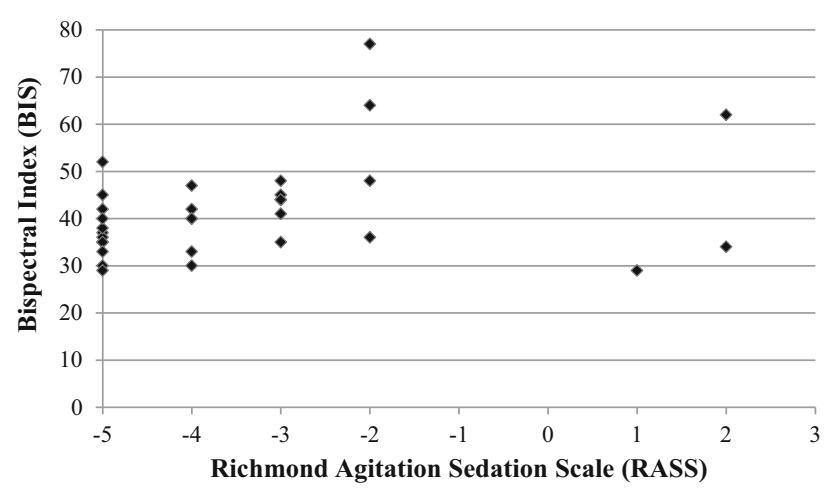

Fig. 4 BIS versus RASS scatter plot. Pearson correlation $=0.27$ $(p=0.14)$

results suggest a potential role for BIS in critically ill patients for whom therapeutic paralysis may otherwise mask inadequate sedation. BIS ${ }^{\mathrm{TM}}<60$ was shown to be highly sensitive for identifying patients with deeper levels of sedation (RASS -5 to -2 ) and provides some reassurance that these patients may experience less awareness while paralyzed. Conversely, our study only observed three patients with $\mathrm{BIS}^{\mathrm{TM}}>60$, limiting our ability to comment on the ability of BIS ${ }^{\mathrm{TM}}$ to identify inadequate sedation reliably. Where applicable, this is reflected in the wide confidence intervals and reflects our uncertainty of the sensitivity and specificity of the total population based on our observations in this study population. While we narrowly defined inadequate sedation as RASS -1 to +4 , no attempt was made to further define the optimal level of sedation during therapeutic paralysis nor does this study attempt to address the target BIS ${ }^{\mathrm{TM}}$ range to mitigate oversedation.

There was a weak correlation observed between BIS during paralysis and RASS upon emergence from paralysis but statistical significance was not achieved as we were not powered to detect such a small magnitude of correlation (Fig. 4). The correlation observed in this study was weaker than that found in most previously published studies conducted in non-paralyzed ICU patients [13-16]. The likely explanation is the difference in the ability of RASS and BIS $^{\mathrm{TM}}$ to detect differences in level of sedation throughout the entire spectrum of sedation and agitation. BIS ${ }^{\mathrm{TM}}$ quantifies levels of deep sedation and anesthesia, whereas RASS is designated to differentiate levels of agitation. A study conducted in 72 volunteers given varying doses of propofol, midazolam, isoflurane, and alfentanil found the relationship between the probability of recall or

Table 3 Sensitivity and specificity for light to deep sedation

\begin{tabular}{|c|c|c|c|c|}
\hline & & \multicolumn{2}{|l|}{ RASS on emergence from paralysis } & \\
\hline & & $\begin{array}{l}\text { Unarousable to light sedation (RASS }-5 \\
\text { to }-2 \text { ) }\end{array}$ & $\begin{array}{l}\text { Drowsy to agitated (RASS }-1 \text { to } \\
+2)\end{array}$ & \\
\hline \multirow[t]{3}{*}{$\begin{array}{l}\text { Last BIS on } \\
\text { NMBA }\end{array}$} & $\mathrm{BIS}<60^{\mathrm{a}}$ & 26 & 2 & $\begin{array}{l}\text { Positive predictive } \\
\text { value }=92.9 \%\end{array}$ \\
\hline & $\mathrm{BIS} \geq 60^{\mathrm{a}}$ & 2 & 1 & $\begin{array}{l}\text { Negative predictive } \\
\text { value }=33.3 \%\end{array}$ \\
\hline & & $\begin{array}{l}\text { Sensitivity }=92.9 \%(95 \% \text { CI } \\
83.3-100)\end{array}$ & $\begin{array}{l}\text { Specificity }=33.3 \%(95 \% \text { CI } \\
0-86.7)\end{array}$ & \\
\hline
\end{tabular}

$B I S$ Bispectral index, $C I$ confidence interval, NMBA neuromuscular blocking agent, RASS Richmond Agitation Sedation Scale

${ }^{a}$ BIS $<60$ is considered consistent with general anesthesia or deep anesthesia per device manufacturer [18] 
consciousness and BIS ${ }^{\mathrm{TM}}$ to be sigmoidal across the entire range of BIS ${ }^{\mathrm{TM}}$ [21]. Thus, at lower BIS ${ }^{\mathrm{TM}}$ values, which were observed in the majority of this cohort, there does not appear to be a strong correlation between BIS $^{\mathrm{TM}}$ and behavioral measures of sedation.

The apparent discrepancy between sensitivity and correlation results may be explained by fundamental differences between the tests. Sensitivity examined the probability of correspondence between ranges of BIS ${ }^{\mathrm{TM}}$ and RASS scores (e.g., BIS ${ }^{\mathrm{TM}}<60$ vs RASS -2 to -5 ) whereas correlation tested the correspondence between scores (e.g., BIS ${ }^{\mathrm{TM}} 40$ vs RASS -4) throughout the range. Therefore, BIS ${ }^{\mathrm{TM}}$ does not appear to be capable of precisely predicting the level of sedation; however, in clinical terms, the sensitivity of BIS ${ }^{\mathrm{TM}}<60$ for predicting light to deep sedation (RASS -2 to -5 ) suggests a reasonable initial goal and target for monitoring and sedation titration.

These findings may also illustrate a limitation to BIS ${ }^{\mathrm{TM}}$ monitoring in critically ill patients. BIS ${ }^{\mathrm{TM}}$ was initially derived from multivariate statistical models based on data from EEG and behavioral scales in subjects receiving various hypnotic agents and anesthetic protocols [18, 22, 23]. However, the patient population used to derive BIS ${ }^{\mathrm{TM}}$ comprised healthy volunteers and surgical patients; thus, cautious, skeptical extrapolation to the ICU patient is necessary. Cerebral ischemia, hypoxemia, and sepsis are factors that may cause diffuse cerebral slowing resulting in lower BIS and RASS [22]. Patients with intracranial hypertension or a persistently obtunded state were excluded to reduce the effects of neurologic injury on the findings. Moreover, there is evidence that administration of endotoxin in healthy volunteers (eliciting elevations in body temperature, tumor necrosis factor- $\alpha$, cortisol, and interleukin-6) resulted in increased non-rapid-eye-movement (delta) sleep and decreased wakefulness [24]. It is highly plausible that a similar state of inflammation and acute phase reactant release is present in the critically ill patient. The implications of these effects on the relationship between RASS and BIS ${ }^{\mathrm{TM}}$ and the probability of awareness or wakefulness in this patient population remain unclear.

Nine patients in the study had discordant RASS and $\mathrm{BIS}^{\mathrm{TM}}$ values (RASS -3 to +4 despite $\mathrm{BIS}^{\mathrm{TM}}<60$ ). Three patients were unique for large burn wounds and for receiving relatively low doses of sedative and analgesic medications. The former factor may account for their falsely depressed $\mathrm{BIS}^{\mathrm{TM}}$, while the latter factor likely accounts for lighter levels of sedation on emergence from paralysis. Another common finding was that four of these nine patients had history of alcohol or drug abuse, which may represent an unknown risk factor for BIS ${ }^{\mathrm{TM}}$ and RASS discordance.
Neuromuscular blockade may have also falsely depressed the values observed for BIS as paralysis effectively ablated electromyographic activity. This possibility was reported in a small proportion of volunteers that were paralyzed with rocuronium without sedation [17]. In order to account for possible 'interference,' this study was designed without presumption of a correlation or threshold between any BIS value and any level of sedation. Furthermore, pacemakers, heating blankets, and hypothermia have been reported to cause false changes in BIS $^{\mathrm{TM}}$ [25]. The administration of opioids has also been demonstrated to have no effect on BIS ${ }^{\mathrm{TM}}$, although concurrent use of opioids with propofol has been shown to contribute greatly to loss of consciousness [26-28]. Since BIS ${ }^{\mathrm{TM}}$ technology has been modified to incorporate new data on EEG response and novel anesthetic drugs and drug combinations, it is unknown whether these inaccuracies remain for newer generations of BIS ${ }^{\mathrm{TM}}$ [29]. The results of this study highlight the potential effect of these and other practical challenges.

There were a number of limitations to this study. Most notably, it was an observational study design with a small sample size, thus limiting the conclusions that may be drawn from the results. Second, in the absence of a gold standard for measuring level of sedation during therapeutic paralysis, RASS at the time of emergence from paralysis was utilized as a surrogate for level of sedation during paralysis. While imperfect, RASS upon emergence provides a crude indicator of sedation, likelihood of recall, and possibility of awareness. This study does not directly address recall of paralysis; it would be logistically difficult to conduct follow-up interviews given the high mortality rate of the cohort. This study is also limited by the heterogeneity in defining emergence from paralysis. The decision not to rely solely on TOF alone was based on the imprecision and inaccuracy of this tool in critically ill patients; a prospective study design would likely necessitate similar compromises [30]. Including patients that received one-time or increasing dosages of sedatives or analgesics after cessation of NMBAs may have biased the results to suggest deeper levels of sedation on emergence from paralysis than were actually present during paralysis. However, none of the 15 patients with $\mathrm{BIS}^{\mathrm{TM}}<60$ during paralysis and constant analgesic and sedative exposure were inadequately sedated (RASS -1 to +4 ) upon emergence from paralysis. This finding suggests that the inclusion criteria did not significantly impact the results. Lastly, the cohort was a small subset $(7.1 \%)$ of all patients receiving NMBAs in the ICU. It is possible that BIS monitoring was ordered for patients that were considered high risk by clinicians that were expressly sensitive to the possibility of inadequate sedation. Therefore, these findings may not be representative of the larger population. 
This study highlights the risk of inadequate sedation during therapeutic paralysis. The results further suggest an implied risk of awareness, even in a small cohort. The recent re-emergence of therapeutic paralysis in the context of relative unfamiliarity and infrequent use further increases the probability of poor management. Strategies that may mitigate risk of inadequate sedation include ensuring target sedation prior to paralysis, periodic cessation of NMBAs, amendment of administration instructions for concurrent sedative orders to avoid titration based on behavioral sedation assessment tools, limiting duration of paralysis, and educating staff. Moreover, future studies utilizing NMBAs as an intervention may assess the risk of inadequate sedation and/or recall of paralysis as a safety endpoint.

There appears to be a disquieting discrepancy between the extremely low rate of awareness achieved in the operating room $(0.24 \%)$ [31] and the relatively high rate (36\%) [4] observed in critically ill patients that required therapeutic paralysis. Studies guiding the accurate detection and prevention of awareness during paralysis in the ICU patient are severely lacking. Research in this area is complicated by difficulty in measuring adequate levels of sedation, intrinsic complexity in defining achievement of sedation goals in the paralyzed patient, the high mortality and morbidity in this patient population, and the relative infrequency of continuous NMBA use. Prospective, randomized trials are needed to assess the utility of BIS ${ }^{\mathrm{TM}}$ for ensuring adequate sedation and reducing recall in patients receiving NMBA in the ICU. Future research may identify risk factors for inadequate sedation or recall of paralysis, risk factors associated with discordance between BIS $^{\mathrm{TM}}$ and true level of sedation, and the cost effectiveness of $\mathrm{BIS}^{\mathrm{TM}}$ in this setting. At present, there is no well defined sedation goal for patients receiving NMBAs in the ICU, and the optimum level of sedation in this population remains to be determined.

\section{Conclusion}

In this small, retrospective observational study we observed that one in ten critically ill patients receiving therapeutic paralysis may be inadequately sedated. In this study, BIS ${ }^{\mathrm{TM}}$ provided high sensitivity for unarousable to light levels of sedation but our data was insufficient to make meaningful conclusions about the ability of BIS ${ }^{\mathrm{TM}}$ to detect inadequate sedation.

It is likely that similar to other strategies of managing sedation and analgesia in paralyzed patients, BIS ${ }^{\mathrm{TM}}$ is confounded by many factors and is not reliable enough be used as the sole method to mitigate the risk of inadequate sedation. However, BIS ${ }^{\mathrm{TM}}$ monitoring may serve as a useful adjunctive measure of sedation in patients receiving therapeutic paralysis. Future studies are needed to validate the utility and constraints of BIS $^{\mathrm{TM}}$ in this patient population.

Acknowledgments The authors would also like to acknowledge Dr Cathy Din, Dr Patricia Parker, Dr Rachelle Firestone, Dr Kathie Le and Dr Erin Nagle for their contributions to this study.

Author contributions Dr Tasaka was directly involved in design of the study, data collection, data analysis, data interpretation, and led the preparation of the manuscript.

Dr Duby was directly involved in design of the study, data collection, data interpretation, and writing and critical review of the manuscript draft. He also served as a project mentor to Dr Tasaka.

Dr Pandya made substantial contributions to the design of the study and critical review of the manuscript draft.

Dr Wilson made substantial contributions to study design, data analysis, and critical review of the manuscript draft.

Dr Hardin made substantial contributions to study design, interpretation of data, and writing and critical review of the manuscript draft.

\section{Compliance with Ethical Standards}

Ethical approvals Approval of this study was granted by the Institutional Review Board and the need for informed consent was waived (IRB ID\# 534116).

Conflict of interest Dr Tasaka, Dr Duby, Dr Pandya, Dr Wilson and Dr Hardin do not have any conflicts of interest to disclose.

Funding The project described was supported in part by the National Center for Advancing Translational Sciences (NCATS), National Institutes of Health (NIH), through Grant \#UL1 TR000002.

Open Access This article is distributed under the terms of the Creative Commons Attribution-NonCommercial 4.0 International License (http://creativecommons.org/licenses/by-nc/4.0/), which permits any noncommercial use, distribution, and reproduction in any medium, provided you give appropriate credit to the original author(s) and the source, provide a link to the Creative Commons license, and indicate if changes were made.

\section{References}

1. Murray MJ, Cowen J, DeBlock H, et al. Clinical practice guidelines for sustained neuromuscular blockade in the adult critically ill patient. Crit Care Med. 2002;30(1):142-56.

2. Papazian L, Fore JM, Gacouin A, et al. Neuromuscular blockers in early acute respiratory distress syndrome. NEJM. 2010;363(12):1107-16.

3. Barr J, Fraser GL, Puntillo K, et al. Clinical practice guidelines for the management of pain, agitation, and delirium in adult patients in the intensive care unit. Crit Care Med. 2013;41:263-306.

4. Wagner BKJ, Zavotsky KE, Sweeney JB, Palmeri BA, Hammond JS. Patient recall of therapeutic paralysis in a surgical critical care unit. Pharmacotherapy. 1998;18(2):358-63.

5. Hardin KA, Seyal M, Stewart T, Bonekat HW. Sleep in critically ill chemically paralyzed patients requiring mechanical ventilation. Chest. 2006;129(6):1468-77. 
6. Avidan MS, Zhang L, Burnside BA, et al. Anesthesia Awareness and the Bispectral Index. N Engl J Med. 2008;358(11):1097-108.

7. Avidan MS, Jacobsohn E, Glick D, et al. Prevention of intraoperative awareness in a high-risk surgical population. $\mathrm{N}$ Engl $\mathrm{J}$ Med. 2011;365(7):591-600.

8. Schuller PJ, Newell S, Strickland PA, Barry JJ. Response of bispectral index to neuromuscular block in awake volunteers. Br J Anaesth. 2015;115(Suppl 1):i95-103.

9. Simmons LE, Richard RR, Prato BS, Fraser G. Assessing sedation during intensive care unit mechanical ventilation with the Bispectral Index and the Sedation-Agitation Scale. Crit Care Med. 1999;27(8):1499-504.

10. Riker RR, Fraser GL, Simmons LE, Wilkins ML. Validating the sedation-agitation scale with the bispectral index and visual analog scale in adult ICU patients after cardiac surgery. Intensive Care Med. 2001;27:853-8.

11. Frenzel D, Greim Clemens A, Sommer C, Bauerle K, Roewer N. Is the bispectral index appropriate for monitoring the sedation level of mechanically ventilated surgical ICU patients? Intensive Care Med. 2002;28:178-83.

12. Chisholm CJ, Zurica J, Mironov D, Sciacca RR, Ornstein E, Heyer EJ. Comparison of electrophysiologic monitors with clinical assessment of level of sedation. Mayo Clin Proc. 2006;81(1):46-52.

13. Haenggi M, Ypparila-Wolters H, Bieri C, Steiner C, Takala J, Korhonen I, Jakob SM. Entropy and bispectral index for assessment of sedation, analgesia and the effects of unpleasant stimuli in critically ill patients: an observational study. Crit Care. 2008;12(5):R119.

14. Arbour R, Waterhouse J, Seckel MA, Bucher L. Correleation between the Sedation-Agitation Scale and the Bispectral Index in ventilated patients in the intensive care unit. Heart Lung. 2009;38:336-45.

15. Trouiller P, Fangio P, Paugam-Burtz C, et al. Frequency and clinical impact of preserved bispectral index activity during deep sedation in mechanically ventilated ICU patients. Intensive Care Med. 2009;35:2096-104.

16. Karamchandani K, Rewari V, Trikha A, Batra RK. Bispectral index correlates well with Richmond agitation sedation scale in mechanically ventilated critically ill patients. J Anesth. 2010;24:394-8.

17. Yaman F, Ozcan N, Ozcan A, Kaymak C, Basar H. Assessment of correlation between bispectral index and four common sedation scales in mechanically ventilated patients in ICU. Eur Rev Med Pharmacol Sci. 2012;16:660-6.

18. Kelley SD. Monitoring consciousness using the Bispectral Index ${ }^{\text {TM }}$ during anesthesia. 2nd ed. Boulder: Covidien; 2010.

19. Sessler CN, Gosnell MS, Grap MJ, Brophy GM, O'Neal PV, Keane KA, Tesoro EP, Elswick RK. The Richmond Agitation-
Sedation Scale: validity and reliability in adult intensive care unit patients. Am J Respir Crit Care Med. 2002;166(10):1338-44.

20. Vincent JL, de Mendonça A, Cantraine F, Moreno R, Takala J, Suter PM, Sprung CL, Colardyn F, Blecher S. Use of the SOFA score to assess the incidence of organ dysfunction/failure in intensive care units: results of a multicenter, prospective study. Crit Care Med. 1998;26(11):1793-800.

21. Glass PS, Bloom M, Kearse L, Rosow C, Sebel P, Manberg P. Bispectral analysis measures sedation and memory effects of propofol, midazolam, isoflurane, and alfentanil in healthy volunteers. Anesthesiology. 1997;86:836-47.

22. Rosow C, Manberg PJ. Bispectral index monitoring. Anesthiol Clin N America. 2001;19(4):947-66.

23. Rampil IJ. A primer for EEG signal processing in anesthesia. Anesthesiology. 1998;89:980-1002.

24. Pollmächer T, Schreiber W, Gudewill S, Vedder H, Fassbender K, Wiedemann K, Trachsel L, Galanos C, Holsboer F. Influence of endotoxin on nocturnal sleep in humans. Am J Physiol. 1993;264:R1077-83.

25. Duarte LTD, Saraiva RA. When the bispectral index can give false results. Rev Bras Anestesiol. 2009;59(1):99-109.

26. Lysakowski C, Dumont L, Pellegrini M, Clergue F, Tassonyi E. Effects of fentanyl, alfentanil, remifentanil and sulfentail on loss of consciousness and bispectral index during propofol induction of anaesthesia. Br J Anaesth. 2001;86(4):523-7.

27. Koitabashi T, Johansen JW, Sebel PS. Remifentanil dose/electroencephalogram bispectral response during combined propofol/ regional anesthesia. Anesth Analg. 2002;94(6):150-3.

28. Struys MM, Vereecke H, Moerman A, Jensen EW, Verhaeghen D, De Neve N, Dumortier FJ, Mortier EP. Ability of the bispectral index, autoregressive modeling with exogenous inputderived auditory evoked potentials, and predicted propofol concentrations to measure patient responsiveness during anesthesia during anesthesia with propofol and remifentanil. Anesthesiology. 2003;99(4):802-12.

29. Gelb AW, Leslie K, Stanski DR, Shafer SL. Monitoring of the depth of anesthesia. Chapter 39, Miller's anesthesia, 7th ed. Philadelphia: Churchill Livingstone: 2010. p. 1229-65.

30. Rudis MI, Guslits BG, Zarowitz BJ. Technical and interpretive problems of peripheral nerve stimulation in monitoring neuromuscular blockade in the intensive care unit. Ann Pharmacother. 1996;30:165-72.

31. Avidan MS, Jacobsohn E, Glick D, Burnside BA, Zhang L, Villafranca A, Karl L, Kamal S, Torres B, O'Connor M, Evers AS, Gradwohl S, Lin N, Palanca BJ, Mashour GA, BAGRECALL Research Group. Prevention of intraoperative awareness in a high-risk surgical population. $\mathrm{N}$ Engl $\mathrm{J}$ Med. 2011;365(7):591-600. 